\title{
Ending hepatitis $C$ in the United States: the role of screening
}

This article was published in the following Dove Press journal:

Hepatic Medicine: Evidence and Research

3 July 2014

Number of times this article has been viewed

\section{Phillip O Coffin' \\ Andrew Reynolds ${ }^{2}$}

'San Francisco Department of Public Health, Substance Use Research Unit, San Francisco, CA, USA; 'Project Inform, San Francisco, CA, USA
Correspondence: Phillip O Coffin San Francisco Department of Public Health, 25 Van Ness Ave, Suite 500, San Francisco, CA 94102, USA

$\mathrm{Tel}+\mathrm{I} 4154376282$

Email pcoffin@gmail.com
Abstract: The US faces at least two distinct epidemics of hepatitis C virus infection (HCV), and due largely to revised screening recommendations and novel therapeutic agents, corresponding opportunities. As only 49\%-75\% of HCV-infected persons in the US are aware of their infection, any chance of addressing HCV in the US is dependent upon screening to identify undiagnosed infections. Most HCV in the US consists of longstanding infections among persons born during 1945-1965 who are suffering escalating rates of liver-related morbidity and mortality. Mathematical modeling supports aggressive action to reach and treat these persons to minimize the subsequent burden of advanced liver disease on patients and the health care system. Incident infection is primarily among persons who inject drugs, less than $10 \%$ of whom have been treated for HCV. Expanded screening and treatment of active persons who inject drugs raises the prospect of utilizing "treatment as prevention" to stem the tide of incident HCV infections in this population. HIV-positive men who have sex with men (MSM) represent a population at risk for sexually transmitted $\mathrm{HCV}$ who may also benefit from adjusted screening guidelines to identify both acute and chronic infections. Prisoners also represent a critical population for aggressive screening and treatment. Finally, the two-stage testing algorithm for HCV diagnosis is problematic and difficult for patients and providers to navigate. While emerging therapeutics raise the prospect of reducing $\mathrm{HCV}$-related morbidity and mortality, as well as eliminating new infections, major barriers remain with regard to identifying infections, improving access to treatment, and ensuring payer coverage of costly new therapeutic regimens.

Keywords: HCV screening, HCV treatment, treatment as prevention

\section{Introduction}

The US faces at least two distinct epidemics of hepatitis $\mathrm{C}$ virus infection (HCV), and due largely to novel therapeutic agents, corresponding opportunities. Established HCV infections are dominated by "baby boomers" born from the mid-1940s to the mid-1960s, the vast majority of whom are at low risk of ongoing transmission, but given the length of time they have been infected, high risk of the sequelae of advancing liver disease. ${ }^{1}$ New infections in the US are almost the exclusive provenance of persons who inject drugs (PWIDs), and those who continue to inject risk secondary transmission of $\mathrm{HCV}^{2}$ Additionally, there is increasing evidence that HIV-positive men who have sex with men (MSM) represent an initial group at risk of apparent sexual transmission of $\mathrm{HCV}^{3}$ If we dramatically improve screening and utilize novel therapeutics with simplified regimens, low toxicity, and high cure rates, we have the opportunity to reduce the morbidity and mortality of established infections and reduce incidence by treating those at risk of secondary transmission. 
HCV has historically received little attention among public health authorities in the US largely due to limited funding. Viral hepatitis receives less than $3 \%$ of the funding HIV receives from the Centers for Disease Control and Prevention (CDC). ${ }^{1}$ Some recent changes, including the Patient Protection and Affordable Care Act (ACA) and new screening recommendations from the $\mathrm{CDC}$ and the US Preventive Health Services Task Force (USPSTF), ${ }^{4,5}$ provide a real opportunity to improve both screening and treatment of HCV. The ACA may increase the number of insured people in the US by as much as 30 million, ${ }^{4}$ with a principal focus on those with lower incomes and youth, two groups at elevated risk of $\mathrm{HCV}^{6,7}$ Moreover, the ACA requires all insurers to cover preventative services given a grade of A or B by the USPSTF, which includes the new CDC HCV screening guidelines. Regarding screening, we have known for some time that behavioral risk factor-based screening was missing the majority (49\%-75\%) of $\mathrm{HCV}$ infections in the US. ${ }^{1,8}$ The reasons for this failure are speculative, but likely include at least some factors particular to US health care, such as legal, economic, and social stigma related to selected risk behaviors (eg, obtaining life insurance may be extremely difficult for any patient who admits to a history of illicit substance use, and until the ACA, many insurers would not cover patients with preexisting conditions). The new approach includes the risk factor-based guidelines as well as screening all persons born from 1945-1965, a population believed to include $75 \%$ of all $\mathrm{HCV}$ infections in the US. While this change only directly affects what we will refer to as "established infections", the attention to HCV screening may improve adherence to traditional screening guidelines as applied to PWIDs and other risk groups. Improved screenings of PWIDs in the US is particularly important as the nation is experiencing a dramatic increase in heroin use subsequent to an epidemic of opioid analgesic dependence. ${ }^{9}, 10$

\section{Reducing morbidity and mortality}

Three-quarters of the 3-4 million persons in the US infected with HCV were born from 1945-1965. ${ }^{11}$ Several distinct HCV models, including one by the first author, suggest that this population of $\mathrm{HCV}$-infected persons is resulting in a formidable burden of liver-related cirrhosis, cancer, and death that will peak by 2030 and then finally begin to decline due to mortality (Figure 1). ${ }^{12-14}$ The US is already witnessing the impact of this epidemic. Estimates of annual HCV-related deaths are as high as $80,000,{ }^{15}$ well in excess of any model predictions, suggesting that the true extent of the epidemic will be well beyond the predictions of these conservative models.

A notable finding from these models is that improvements in HCV treatment will fail to substantially affect this epidemic of end-stage liver disease without substantial improvements in screening to detect those aging persons prior to the development of hepatic cirrhosis. Screening of the population born from 1945-1965, even limited to treatment with pegylated-interferon and ribavirin, has been estimated to reduce the cumulative total of HCV-related deaths from 591,000 to 509,000 deaths (a reduction of 82,000 , or $14 \%$ ) when compared to risk factor-based screening. ${ }^{12}$ Based on a model developed by the lead author of this paper, therapies providing a sustained viral response (SVR) rate of $80 \%$ would prevent upwards of $7 \%$ of $\mathrm{HCV}$-related deaths, an estimate that doubles with broadened screening efforts (Figure 1). ${ }^{14}$ In a variation on this model, if $80 \%$ of those found to have $\mathrm{HCV}$ were referred to specialty care, $80 \%$ attended, $80 \%$ were treated, and $80 \%$ achieved SVR, cumulative HCVrelated mortality would be reduced by $12.4 \%$; the addition of screening of $60 \%$ of the general US adult population would result in a $19.1 \%$ reduction in mortality (Figure 1). These results strongly suggest that broadened screening, such as that recently approved by major US health care bodies, is necessary to actualize the expected public health benefits of improved HCV therapeutics. Even in the context of cure rates approaching $100 \%$, as we anticipate with regimens in the immediate future, ${ }^{16}$ the public health benefits remain dependent on finding those with undiagnosed HCV.

Another way to conceptualize care for this population is through the perspective of the HIV care continuum. The HIV care continuum, also referred to as the cascade of care, has been used by the Institute of Medicine and others to gauge the quality of HIV prevention and care provided at local, regional, and national levels. ${ }^{17,18}$ The results suggest several points of intervention to improve the rate of viral suppression in a community and maximize the potential to use "treatment as prevention" (TasP). Most persons with established HCV infection in the US are no longer at high-risk of transmitting $\mathrm{HCV}$ to others (the median duration of injecting drugs in the US is $10-15$ years and most $\mathrm{HCV}$-infected persons require substantially longer to progress to significant liver disease); ${ }^{19}$ thus, TasP does not apply to the majority of HCV-infected persons in the US. However, the cascade can also serve as a guide to the utilization of HCV screening and care services. Figure 2 illustrates one such cascade, including measures that could be readily implemented in an integrated health system (due to insufficient funding and limited reporting 

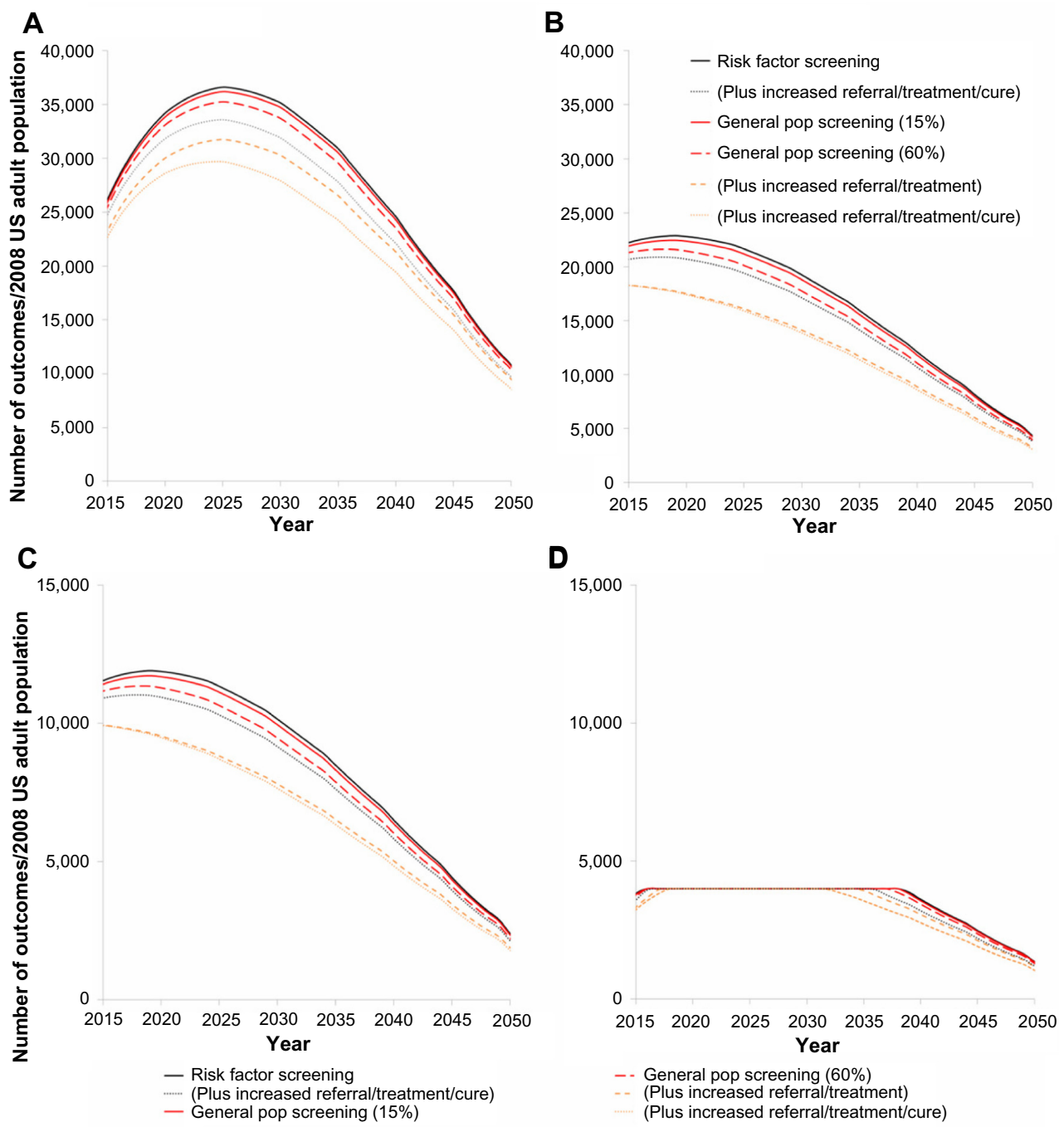

Figure I Impact of improved screening, referral, and treatment of hepatitis $C$ on related morbidity.

Notes: (A) Liver-related deaths; (B) decompensated cirrhosis; (C) hepatocellular carcinoma; (D) liver transplants. End-stage liver disease outcomes under: I) risk factorbased screening plus ( Ia) improved referral, treatment, and cure rates; 2 ) addition of screening of I5\% of the general population; or 3 ) addition of screening $60 \%$ of the general population plus (3a) improved referral and treatment rates and (3b) improved cure rates, assuming intervention was initiated in 20II. Coffin PO, Scott JD, Golden MR, Sullivan SD, Cost-effectiveness and population outcomes of general population screening for hepatitis C, Clin Infect Dis, 20I2;54(9):I259-127I, by permission of Oxford University Press. ${ }^{14}$

Abbreviation: pop, population.

requirements under various state laws, public health surveillance for viral hepatitis does not currently possess the capacity to track much HCV data, including any negative test results). Data from a large health care provider, Kaiser Permanente (Oakland, CA, USA), have been used to illustrate the screening portion of this cascade, suggesting increased screening in recent years, ${ }^{20}$ but have not yet been applied to the full continuum of $\mathrm{HCV}$ care. The proportion that could be cured by HCV treatment in such a model is limited only by the proportion that would be considered eligible for treatment and by the SVR of dominant therapies.

Historical estimates suggest that less than $2 \%$ of persons with $\mathrm{HCV}$ are cured through treatment (based on estimates that $25 \%$ of persons with $\mathrm{HCV}$ are detected through screening, ${ }^{8} 77 \%$ are referred to $\mathrm{HCV}$ care, $66 \%$ attend care, ${ }^{21}$ $26 \%$ initiate care, ${ }^{22,23}$ and around $60 \%$ achieve SVR). A more recent analysis suggested that as many as $9 \%$ of persons with HCV may achieve SVR ${ }^{24}$ In contrast, the HCV cascade suggests that, in the setting of therapeutics available in 2013, optimal screening and clinical management could result in cure in up to $30 \%$ of persons with chronic HCV. Novel therapies are expected to vastly change these estimates. The absence of interferon and/or ribavirin from regimens will allow many of the $13 \%$ with absolute contraindications to those therapies, ${ }^{25}$ and an additional $50 \%$ with relative contraindications, ${ }^{22,23,26}$ to seriously consider treatment, while easier regimens are expected to vastly increase the number of patients willing to engage in treatment. In the setting of 


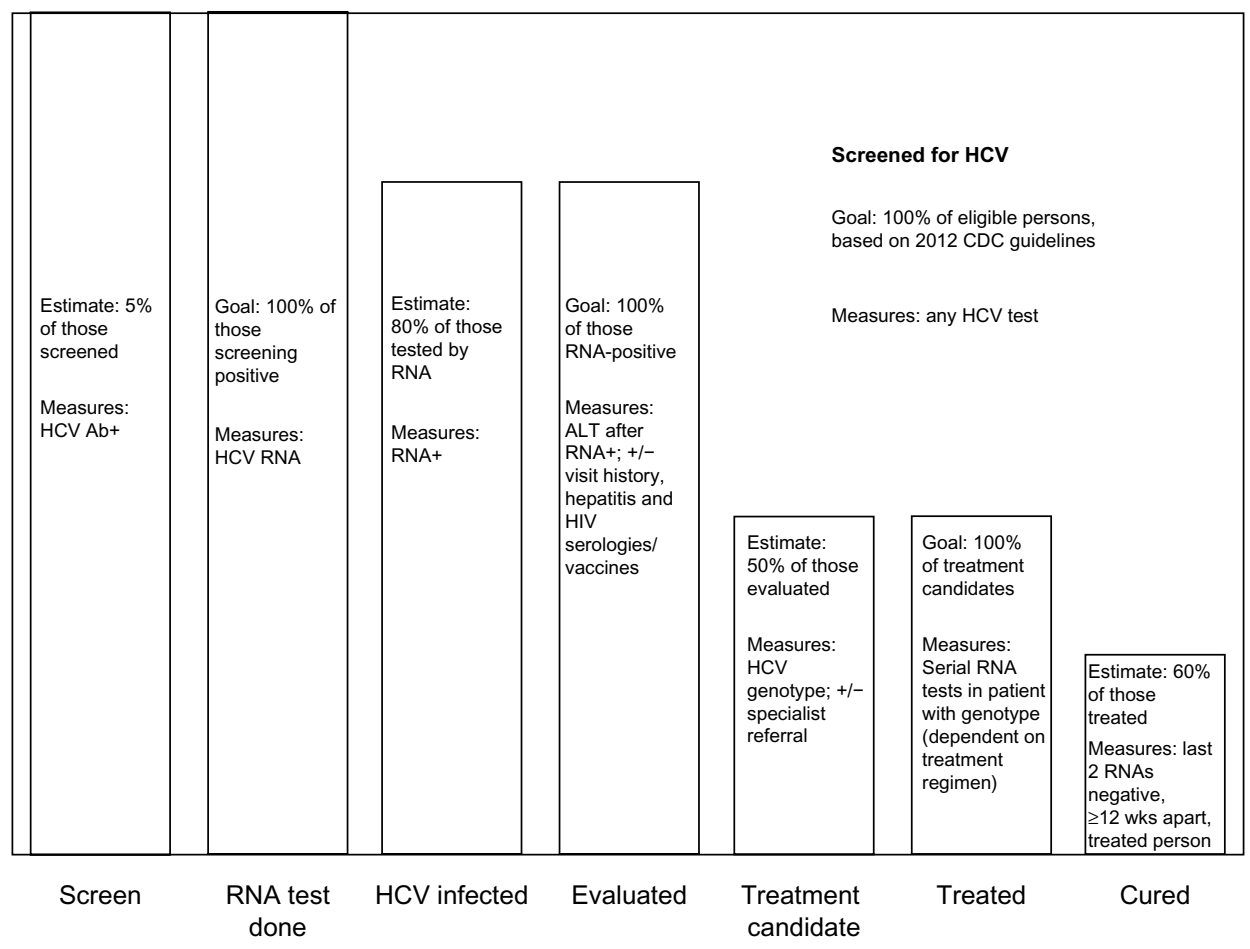

Figure 2 Hepatitis $\mathrm{C}$ screening and treatment cascade.

Abbreviations: Ab, antibody; ALT, alanine aminotransferase; CDC, United States Centers for Disease Control and Prevention; HCV, hepatitis C virus; HIV, human immunodeficiency virus; RNA, ribonucleic acid; wks, weeks.

improved SVR, these changes may increase the percentage that could be cured through comprehensive HCV screening and care to as high as $40 \%-80 \%$. As in the case of HIV, the population-level impact of maximizing $\mathrm{HCV}$ outcomes along the cascade is expected to have significant impact on HCV-associated morbidity and mortality, potentially lower transmission, and reduce long-term health care costs. In contrast to HIV, HCV treatment is believed to be curative, which suggests the possibility of more significant socioeconomic and epidemic benefits of improved screening and treatment in the long run.

The advent of novel therapeutics is critical to our efforts to minimize this epidemic of liver disease. High cure rates with more tolerable regimens will not only reduce sequelae among those treated for $\mathrm{HCV}$, but are also expected to entice more HCV-infected persons to seek and accept treatment, thus addressing at least part of the linkage to care gap. Furthermore, the relative simplicity of managing interferonfree therapies will allow a wider range of providers to manage and treat HCV (there are no restrictions in the US on which medical providers can treat patients for $\mathrm{HCV}$, but treatment historically has been offered largely by hepatologists and gastroenterologists because of the complexities involved in managing interferon-based therapies and the historical goal of deferring treatment to await novel therapeutic agents by performing staging liver biopsies). Two new HCV antivirals, sofosbuvir and simeprevir, were approved for use in the US in 2013 and additional agents are expected to be approved in $2014,{ }^{27}$ providing short-course, interferon-free, low side effect, potent options for most HCV-infected persons. Many of the anticipated regimens have similar, high efficacy in populations that respond poorly to interferon-based therapy (eg, those with hepatic cirrhosis or coinfection with HIV), thus expanding the population likely to benefit from treatment beyond that estimated in extant mathematical models. However, the benefits of these dramatic shifts cannot be fully realized without identifying those unaware of their infection through a dramatic expansion in HCV screening.

\section{TasP}

In contrast to the vast population of older adults with established HCV infection and low risk of transmission, PWIDs who are actively injecting drugs remain at high risk for both acquisition and transmission of HCV. The CDC estimates close to 18,000 new HCV infections per year, almost exclusively among PWIDs, with a $44 \%$ increase in the number of acute cases from 2010 to $2011 .^{28}$ Several outbreaks of HCV infection among groups of PWIDs have also been noted in recent years, due in part to the vast expansion in opioid prescribing and subsequent transition to injection drug use that 
has occurred in communities across the US..$^{29}$ PWIDs who initiated drug use with prescription opioids are less likely than long-time heroin users to perceive themselves as at-risk for blood-borne viral infections, and thus represent a large cohort of potential infections. ${ }^{30}$

Syringe exchange has served as the bulwark against HIV infection for PWIDs worldwide. This intervention has been so effective for HIV prevention among this population that most HIV infections among PWIDs in localities with high-quality syringe access may be due to sexual rather than parenteral transmission. ${ }^{31}$ Unfortunately, syringe exchange has not proven nearly as effective for preventing the transmission of HCV. The most optimistic findings suggest that decades of high-volume syringe services have delayed HCV infection such that most PWIDs do not become infected until they have been injecting drugs for about 2 years; given that most PWIDs inject for at least 10 years, syringe exchange does not prevent eventual infection. ${ }^{32,33}$ The suspected reasons for the relative failure of syringe exchange in preventing $\mathrm{HCV}$ include the high viral load and high prevalence of infection in the community, as well as the hardiness of the virion outside of the body. $\mathrm{HCV}$ can survive up to 7 days at $37^{\circ} \mathrm{C}$ and up to 6 weeks at $40^{\circ} \mathrm{C}$ and $22^{\circ} \mathrm{C}$ after drying on inanimate surfaces $^{34}$ and is found in substantial quantities on all injection equipment, such as cookers, cotton, alcohol pads, and rinse water. ${ }^{35,36}$ These factors likely make HCV much more easy to transmit through practices such as "backloading", in which PWIDs divide drugs by filling one syringe, pulling out the plunger, and drawing up pre-established amounts of the drug into each personal syringe. ${ }^{37}$ To prevent $\mathrm{HCV}$ through syringe exchange services likely requires not only many decades of ready availability of sterile syringes, needles, alcohol pads, water, cotton swabs, and cookers, but also aggressive educational campaigns to avoid any potential contamination of these materials with other people's supplies. As evidenced by the ongoing iatrogenic transmission of HCV even in wellregulated health care settings, ${ }^{38-40}$ this may simply be too high of a bar for lay users of injection equipment.

Aggressive screening and treatment, however, have great potential in reducing or eliminating $\mathrm{HCV}$ transmission among PWIDs. Recent data suggests that screening positive for $\mathrm{HCV}$ results in sustained reductions in drug use among PWIDs; ${ }^{41}$ in conjunction with data supporting HCV-based serosorting among PWIDs, these data suggest that screening alone may be helpful in reducing secondary transmission. ${ }^{42}$ Moreover, treatment of active PWIDs for HCV with pegylated-interferon and ribavirin has been found to be cost-effective based on mathematical modeling ${ }^{43}$ Experience with treating active
PWIDs in the US, however, suggests that very few would opt for, be eligible for, and successfully complete interferonbased therapy. ${ }^{44,45}$ There are also ethical concerns with treating a high number of active PWIDs with interferon, as most active PWIDs do not yet have advanced liver disease (as the median duration of injecting is $10-15$ years); ${ }^{19}$ some may never develop liver disease, and there are risks to interferon therapy beyond the relatively transient side effects (eg, permanent hypothyroidism). A more recent modeling exercise examined of the use of novel therapeutics for treating active PWIDs. Treating $8 \%-15 \%$ of HCV-infected active PWIDs annually for $\mathrm{HCV}$ would reduce $\mathrm{HCV}$ prevalence by $75 \%$ over 15 years according to a conservative model that assumed that reinfection rates post-treatment were the same as initial infection rates. ${ }^{46}$ Cohort studies, however, estimate the reinfection rate at $4 \%-6 \%$ per year, ${ }^{2,47}$ which is about half the rate assumed for initial infection, ${ }^{48}$ and those trained in safer injection practices may have even less risk of reinfection. Interferon-free therapies may, if widely available, prove viable for mass treatment of active PWIDs.

If we apply the HCV cascade to active PWIDs, the rate of diagnosis remains poor, linkage to care is abysmal, and very few are treated. Although half to two-thirds of PWIDs are HCV seropositive, at least $49 \%$ are aware of their diagnosis, ${ }^{1}$ around $21 \%$ have been evaluated by a provider proficient in treating $\mathrm{HCV}^{49}$ and only $1 \%-9 \%$ have ever initiated $\mathrm{HCV}$ treatment. Interferon-free therapies are relatively short, easily dosed, well-tolerated, and highly effective. These improvements should lead not only to high cure rates, but substantially higher rates of treatment uptake. Moreover, the simplicity of managing the regimen should lead to a rapid expansion of HCV treatment into the networks of primary care providers caring for underserved populations such as PWIDs, homeless persons, and correctional populations. If we also take advantage of social networks, and enlist PWIDs within a patient's network to get screened and treated, we may further reduce the rate of reinfection. If widely employed, these new therapeutics could signal the end of HCV transmission in the US.

\section{Additional areas of concern HIV-positive MSM}

HIV-positive MSM appear to be at risk for sexual transmission of $\mathrm{HCV}^{50-53}$ Although this is a population that is generally under regular medical care and for whom guidelines, including those related to $\mathrm{HCV}$ screening, are regularly updated, some studies have found that as many as $30 \%$ of HIV-infected patients were unaware of their status. ${ }^{54}$ All HCV-positive 
persons should receive an initial screen for $\mathrm{HCV}$, yet that is not always achieved and it remains unclear how frequently HIV-positive MSM should be screened or if repeat testing should only occur based on clinical suspicion (eg, an elevation in transaminases). Recently released HCV management guidelines from the American Association for the Study of Liver Diseases and the Infectious Disease Society of America recommend annual HCV screening for PWID and HIVinfected MSM. ${ }^{55}$ The European AIDS Treatment Network recommends $\mathrm{HCV}$ antibody screening for all newly diagnosed HIV-positive persons, annual HCV antibody testing and twice annual alanine aminotransferase testing for MSM at risk for acute $\mathrm{HCV}, \mathrm{HCV}$ antibody testing 3 months after diagnosis of a sexually transmitted disease or injection drug use exposure, and HCV RNA testing on suspicion of acute $\mathrm{HCV}^{56}{ }^{56}$ The development of updated HCV recommendations for HIV-infected persons is particularly relevant as coinfection with $\mathrm{HIV}$ and $\mathrm{HCV}$ can result in rapid progression of liver disease $^{54}$ and because early detection may provide a superior chance of cure.

\section{Screening in correctional populations}

Although $\mathrm{HCV}$ seroprevalence among US prisoners is declining, rates still range from $10 \%-41 \%$ and represent $29 \%-33 \%$ of all HCV cases in the country. ${ }^{57}$ Screening guidelines in correctional settings that rely on self-report of injection drug use, a revelation that may raise legal or social difficulties for the incarcerated individual, miss many who should be screened. ${ }^{58}$ In contrast, revised USPSTF guidelines recommend screening all incarcerated persons for $\mathrm{HCV}$, removing the need for self-disclosure. ${ }^{59}$ Routine HCV screening in correctional settings, with access to treatment during incarceration and linkage to care upon release, has the potential to substantially reduce the morbidity, mortality, and transmission of $\mathrm{HCV}^{60}$

\section{Testing algorithm}

Knowledge about one's HCV infection is necessary to progress to treatment, and in one study, was the only independent predictor for receiving HCV treatment. ${ }^{61}$ Such knowledge also predicts serosorting behaviors among PWIDs. ${ }^{42}$ However, surveillance data demonstrate that only about half of those seropositive for $\mathrm{HCV}$ receive confirmatory RNA testing, ${ }^{62,63}$ and even among those receiving appropriate follow-up testing, many do not understand the meaning of the various HCV tests. ${ }^{64}$ For the approximately $20 \%$ of persons who are exposed to HCV but spontaneously clear the infection, a positive HCV antibody test without follow-up
RNA testing may result in unnecessary anxiety, diminished quality of life, ${ }^{65}$ and for PWIDs who go on to serosort with $\mathrm{HCV}$-infected persons, increased risk of subsequent reinfection with $\mathrm{HCV}^{42}$ In addition, strategies utilizing $\mathrm{HCV}$ RNA testing to identify acute HCV infections in susceptible populations should be further developed and promulgated in guidelines and practice. ${ }^{66-68}$ As RNA assays become less expensive and more easily available, we should reconsider testing algorithms to avoid many of the pitfalls associated with the current two-step process of HCV antibody testing followed by HCV RNA testing.

\section{Primary care management}

To care for the increased number of individuals expected to be diagnosed with $\mathrm{HCV}$, primary care providers will need to be able to provide initial management and, ultimately, treatment. Currently, many primary care providers are uncertain what to do following an $\mathrm{HCV}$ diagnosis, including what steps should be taken for counseling, screening, and vaccination for syndemic infections, and appropriate management prior to treatment. To address these challenges, professional societies such as the American Association for the Study of Liver Diseases and Infectious Disease Society of America have developed recommendations for the testing, managing, and treating of $\mathrm{HCV}$ to guide providers who have not specialized in HCV treatment. ${ }^{55}$ Telemedicine has also proven to be an effective tool to support non-specialists in community health care and correctional settings in managing and treating $\mathrm{HCV}^{69}$ Finally, the CDC and other federal agencies are attempting to increase the capacity of primary care providers to manage $\mathrm{HCV}$, through both grants programs and technical assistance, a process that should alleviate some of the constraints on HCV screening and management. ${ }^{70}$

\section{Costs of HCV treatment}

The most substantial barrier to recognizing the benefits of enhanced screening and new therapeutics is likely to be the high cost of novel therapeutic agents. New medications are expected to cost in excess of US\$100,000 for a course of treatment, ${ }^{71}$ making them out of reach for uninsured populations and an enormous burden on insurers, particularly the public programs caring for a disproportionate share of $\mathrm{HCV}$-infected persons (in an emergency department-based study of birth cohort screening, $16.7 \%$ of publicly insured or uninsured patients were HCV-positive compared with $5.3 \%$ of privately insured patients ${ }^{72}$ ). It remains unclear how health care payers will cover the new medications. They may, for example, require evidence of advanced fibrosis in 
order to pay for treatment or require trials of an interferonbased regimen prior to permitting use of interferon-free therapies. Such decisions would have several unfortunate effects: eg, requiring biopsies would largely restrict HCV treatment to specialists; if patients were required to undergo biopsies, substantially fewer would accept therapy; if advanced fibrosis was required, very few active PWIDs would be treated, and thus we would lose any TasP benefit. While less invasive diagnostics, such as transient elastography, are increasingly found to reliably predict cirrhosis and liver-related events, ${ }^{73}$ these imaging modalities are not routinely available in most health care settings and do not discriminate between each stage of fibrosis. Thus, to achieve the aims of reduced morbidity, mortality, and transmission of HCV would require a sophisticated prior authorization protocol that accounted for the limitations of primary care and the potential benefits of broader HCV treatment in several populations.

\section{Conclusion}

The US is positioned to address twin epidemics of HCV infection, if the health care system can muster engagement in broad screening and payer support for wide treatment of infected persons. The cost-effectiveness of treating longtime infected persons is well-established and justifies an upfront investment to dramatically reduce long-term costs and related mortality. The advent of brief 6-12 week, all oral, well-tolerated, highly potent $\mathrm{HCV}$ regimens offers the opportunity to think beyond disease control and towards eradication of new HCV infections. With improved screening, linkage to care, and treatment we may be able to end $\mathrm{HCV}$ infection in the US within a generation.

\section{Acknowledgments}

The authors thank Moupali Das for her review of the manuscript.

\section{Disclosure}

The authors report no conflicts of interest in this work.

\section{References}

1. Colvin HM, Mitchell AE, editors. Hepatitis and Liver Cancer: A National Strategy for Prevention and Control of Hepatitis $B$ and $C$. Washington, DC: Institute of Medicine; 2010. Available from: http://www.cdc.gov/ hepatitis/pdfs/iom-hepatitisandlivercancerreport.pdf. Accessed May 21, 2014.

2. Page K, Morris MD, Hahn JA, Maher L, Prins M. Injection drug use and hepatitis $\mathrm{C}$ virus infection in young adult injectors: using evidence to inform comprehensive prevention. Clin Infect Dis. 2013;57 Suppl 2: S32-S38.
3. Taylor LE, Swan T, Mayer KH. HIV coinfection with hepatitis C virus: evolving epidemiology and treatment paradigms. Clin Infect Dis. 2012; 55 Suppl 1:S33-S42.

4. Mehmud SM, Neiman D. The Affordable Care Act in brief: a look into January 2014 changes. Benefits Q. 2013;29(2):34-41.

5. Smith BD, Morgan RL, Beckett GA, et al; Centers for Disease Control and Prevention. Recommendations for the identification of chronic hepatitis C virus infection among persons born during 1945-1965. MMWR Recomm Rep. 2012;61(RR-4):1-32.

6. Talwalkar JA. Potential impacts of the Affordable Care Act on the clinical practice of hepatology. Hepatology. 2014;59(5):1681-1687.

7. Degenhardt L, Whiteford HA, Ferrari AJ, et al. Global burden of disease attributable to illicit drug use and dependence: findings from the Global Burden of Disease Study 2010. Lancet. 2013;382(9904): 1564-1574.

8. Hagan H, Campbell J, Thiede H, et al. Self-reported hepatitis C virus antibody status and risk behavior in young injectors. Public Health Rep. 2006;121(6):710-719.

9. Unick GJ, Rosenblum D, Mars S, Ciccarone D. Intertwined epidemics: national demographic trends in hospitalizations for heroin- and opioidrelated overdoses, 1993-2009. PLoS One. 2013;8(2):e54496.

10. Cerdá M, Ransome Y, Keyes KM, et al. Prescription opioid mortality trends in New York City, 1990-2006: examining the emergence of an epidemic. Drug Alcohol Depend. 2013;132(1-2):53-62.

11. Smith BD, Morgan RL, Beckett GA, Falck-Ytter Y, Holtzman D, Ward JW. Hepatitis C virus testing of persons born during 1945-1965: recommendations from the Centers for Disease Control and Prevention. Ann Intern Med. 2012;156(4):263-270.

12. Rein DB, Smith BD, Wittenborn JS, et al. The cost-effectiveness of birth-cohort screening for hepatitis $\mathrm{C}$ antibody in US primary care settings. Ann Intern Med. 2012;156(4):263-270.

13. Davis GL, Alter MJ, El-Serag H, Poynard T, Jennings LW. Aging of hepatitis C virus (HCV)-infected persons in the United States: a multiple cohort model of $\mathrm{HCV}$ prevalence and disease progression. Gastroenterology. 2010;138(2):513-521, 521. e1-e6.

14. Coffin PO, Scott JD, Golden MR, Sullivan SD. Cost-effectiveness and population outcomes of general population screening for hepatitis C. Clin Infect Dis. 2012;54(9):1259-1271.

15. Vera-Llonch M, Martin M, Aggarwal J, et al. Health-related quality of life in genotype 1 treatment-naïve chronic hepatitis $\mathrm{C}$ patients receiving telaprevir combination treatment in the ADVANCE study. Aliment Pharmacol Ther. 2013;38(2):124-133.

16. Gilead Sciences. Once Daily Fixed Dose Combination of Sofosbuvir and Ledipasvir. Foster City, CA: Gilead Sciences; 2013. Available from: http://www.gilead.com/news/press-releases/2013/12/gilead-announces-svr12-rates-from-three-phase-3-studies-evaluating-a-oncedailyfixeddose-combination-of-sofosbuvir-and-ledipasvir-for-genotype1-hepatitis-c-patients. Accessed May 21, 2014.

17. Institute of Medicine. Monitoring HIV Care in the United States: a Strategy for Generating National Estimates of HIV Care and Coverage. Washington, DC: The National Academies Press; 2012. Available from: http://www.iom.edu/Reports/2012/Monitoring-HIV-Care-in-theUnited-States-A-Strategy-for-Generating-National-Estimates-of-HIVCare-and-Coverage.aspx. Accessed May 21, 2014.

18. Office of the Press Secretary. Executive Order - HIV Care Continuum Initiative. Washington, DC: The White House; 2013. Available from: http://www.whitehouse.gov/the-press-office/2013/07/15/executiveorder-hiv-care-continuum-initiative. Accessed February 19, 2014.

19. Evans JL, Hahn JA, Lum PJ, Stein ES, Page K. Predictors of injection drug use cessation and relapse in a prospective cohort of young injection drug users in San Francisco, CA (UFO Study). Drug Alcohol Depend. 2009;101(3):152-157.

20. Linas BP, Hu H, Barter DM, Horberg M. Hepatitis C screening trends in a large integrated health system. Am J Med. 2014;127(5):398-405.

21. Putka B, Mullen K, Birdi S, Merheb M. The disposition of hepatitis $\mathrm{C}$ antibody-positive patients in an urban hospital. JViral Hepat. 2009;16(11):814-821. 
22. Morrill JA, Shrestha M, Grant RW. Barriers to the treatment of hepatitis C. Patient, provider, and system factors. J Gen Intern Med. 2005;20(8):754-758.

23. Falck-Ytter Y, Kale H, Mullen KD, Sarbah SA, Sorescu L, McCullough AJ. Surprisingly small effect of antiviral treatment in patients with hepatitis C. Ann Intern Med. 2002;136(4):288-292.

24. Yehia B, Schranz A, Umschied C, Re VL. The treatment cascade for people with chronic hepatitis $\mathrm{C}$ infection in the United States. Conference on retrovirus and opportunistic infections; March 3-6, 2014; Seattle, WA.

25. Castelnuovo E, Thompson-Coon J, Pitt M, et al. The cost-effectiveness of testing for hepatitis $\mathrm{C}$ in former injecting drug users. Health Technol Assess. 2006;10(32):iii-iv, ix-xii, 1-93.

26. Irving WL, Smith $\mathrm{S}$, Cater R, et al. Clinical pathways for patients with newly diagnosed hepatitis $\mathrm{C}-$ what actually happens. J Viral Hepat. 2006;13(4):264-271.

27. Lawitz E, Poordad FF, Pang PS, et al. Sofosbuvir and ledipasvir fixeddose combination with and without ribavirin in treatment-naive and previously treated patients with genotype 1 hepatitis $\mathrm{C}$ virus infection (LONESTAR): an open-label, randomised, phase 2 trial. Lancet. 2014;383(9916):515-523.

28. United States Centers for Disease Control and Prevention. Surveillance for Viral Hepatitis - United States, 2011. Atlanta, GA: Centers for Disease Control and Prevention; 2013. Available from: http://www.cdc. gov/hepatitis/Statistics/2011Surveillance/. Accessed May 21, 2014.

29. Centers for Disease Control and Prevention (CDC). Notes from the field: risk factors for hepatitis $\mathrm{C}$ virus infections among young adults Massachusetts, 2010. MMWR Morb Mortal Wkly Rep. 2011;60(42): 1457-1458.

30. Pollini RA, Banta-Green CJ, Cuevas-Mota J, et al. Problematic use of prescription-type opioids prior to heroin use among young heroin injectors. Subst Abuse Rehabil. 2011;2(1):173-180.

31. Bacon O, Lum P, Hahn J, et al. Commercial sex work and risk of HIV infection among young drug-injecting men who have sex with men in San Francisco. Sex Transm Dis. 2006;33(4):228-234.

32. Holtzman D, Barry V, Ouellet LJ, et al. The influence of needle exchange programs on injection risk behaviors and infection with hepatitis $\mathrm{C}$ virus among young injection drug users in select cities in the United States, 1994-2004. Prev Med. 2009;49(1):68-73.

33. Falster K, Kaldor JM, Maher L. Hepatitis C virus acquisition among injecting drug users: a cohort analysis of a national repeated crosssectional survey of needle and syringe program attendees in Australia, 1995-2004. J Urban Health. 2009;86(1):106-118.

34. Paintsil E, Binka M, Patel A, Lindenbach BD, Heimer R. Hepatitis C virus maintains infectivity for weeks after drying on inanimate surfaces at room temperature: implications for risks of transmission. J Infect Dis. 2014;209(8):1205-1211.

35. Thibault V, Bara JL, Nefau T, Duplessy-Garson C. Hepatitis C transmission in injection drug users: could swabs be the main culprit? J Infect Dis. 2011;204(12):1839-1842.

36. Doerrbecker J, Behrendt P, Mateu-Gelabert P, et al. Transmission of hepatitis $\mathrm{C}$ virus among people who inject drugs: viral stability and association with drug preparation equipment. J Infect Dis. 2013;207(2): 281-287.

37. Pouget ER, Hagan H, Des Jarlais DC. Meta-analysis of hepatitis C seroconversion in relation to shared syringes and drug preparation equipment. Addiction. 2012;107(6):1057-1065.

38. Smedley EJ, Stelzer-Braid S, Ressler KA, et al. Transmission of hepatitis $\mathrm{C}$ virus to recipients of parenteral vitamin therapy in a primary care facility. J Clin Virol. 2011;51(2):105-109.

39. Fischer GE, Schaefer MK, Labus BJ, et al. Hepatitis C virus infections from unsafe injection practices at an endoscopy clinic in Las Vegas, Nevada, 2007-2008. Clin Infect Dis. 2010;51(3):267-273.

40. Shemer-Avni Y, Cohen M, Keren-Naus A, et al. Iatrogenic transmission of hepatitis $\mathrm{C}$ virus ( $\mathrm{HCV}$ ) by an anesthesiologist: comparative molecular analysis of the HCV-E1 and HCV-E2 hypervariable regions. Clin Infect Dis. 2007;45(4):e32-e38.
41. Bruneau J, Zang G, Abrahamowicz M, Jutras-Aswad D, Daniel M, Roy E. Sustained drug use changes after hepatitis $C$ screening and counseling among recently infected persons who inject drugs: a longitudinal study. Clin Infect Dis. 2014;58(6):755-761.

42. Kim AY, Page K. Hepatitis C virus serosorting in people who inject drugs: sorting out the details. $J$ Infect Dis. 2013;208(12): 1929-1931.

43. Martin NK, Vickerman P, Miners A, et al. Cost-effectiveness of hepatitis $\mathrm{C}$ virus antiviral treatment for injection drug user populations. Hepatology. 2012;55(1):49-57.

44. Charlebois A, Lee L, Cooper E, Mason K, Powis J. Factors associated with $\mathrm{HCV}$ antiviral treatment uptake among participants of a community-based $\mathrm{HCV}$ programme for marginalized patients. $J$ Viral Hepat. 2012;19(12):836-842.

45. Hellard M, Sacks-Davis R, Gold J. Hepatitis C treatment for injection drug users: a review of the available evidence. Clin Infect Dis. 2009;49(4):561-573.

46. Martin NK, Vickerman P, Grebely J, et al. Hepatitis C virus treatment for prevention among people who inject drugs: modeling treatment scale-up in the age of direct-acting antivirals. Hepatology. 2013;58(5):1598-1609.

47. Page K, Osburn W, Evans J, et al. Frequent longitudinal sampling of hepatitis $\mathrm{C}$ virus infection in injection drug users reveals intermittently detectable viremia and reinfection. Clin Infect Dis. 2013;56(3): 405-413.

48. Thorpe LE, Ouellet LJ, Hershow R, et al. Risk of hepatitis C virus infection among young adult injection drug users who share injection equipment. Am J Epidemiol. 2002;155(7):645-653.

49. Mehta SH, Genberg BL, Astemborski J, et al. Limited uptake of hepatitis $\mathrm{C}$ treatment among injection drug users. J Community Health. 2008;33(3):126-133.

50. Cotte L, Chevallier Queyron P, Schlienger I, et al. Sexually transmitted $\mathrm{HCV}$ infection and reinfection in HIV-infected homosexual men. Gastroenterol Clin Biol. 2009;33(10-11):977-980.

51. Alipour A, Rezaianzadeh A, Hasanzadeh J, Rajaeefard A, Davarpanah MA. Sexual transmission of hepatitis C Virus between HIV infected subjects and their main heterosexual partners. Hepat Mon. 2013;13(11):e13593.

52. Centers for Disease Control and Prevention (CDC). Sexual transmission of hepatitis $\mathrm{C}$ virus among HIV-infected men who have sex with men - New York City, 2005-2010. MMWR Morb Mortal Wkly Rep. 2011;60(28):945-950.

53. Witt MD, Seaberg EC, Darilay A, et al. Incident hepatitis C virus infection in men who have sex with men: a prospective cohort analysis, 1984-2011. Clin Infect Dis. 2013;57(1):77-84.

54. Branch AD, Van Natta ML, Vachon ML, et al. Mortality in hepatitis C virus-infected patients with a diagnosis of AIDS in the era of combination antiretroviral therapy. Clin Infect Dis. 2012;55(1):137-144.

55. American Association for the Study of Liver Diseases, Infectious Disease Society of America. Recommendations for Testing, Managing and Treating Hepatitis C. 2014. Available from: http://www.hcvguidelines. org/. Accessed April 18, 2014.

56. European AIDS Treatment Network (NEAT) Acute Hepatitis C Infection Consensus Panel. Acute hepatitis C in HIV-infected individuals: recommendations from the European AIDS Treatment Network (NEAT) consensus conference. AIDS. 2011;25(4):399-409.

57. Varan AK, Mercer DW, Stein MS, Spaulding AC. Hepatitis C seroprevalence among prison inmates since 2001: still high but declining. Public Health Rep. 2014;129(2):187-195.

58. Macalino GE, Dhawan D, Rich JD. A missed opportunity: hepatitis C screening of prisoners. Am J Public Health. 2005;95(10):1739-1740.

59. Whiteford HA, Degenhardt L, Rehm J, et al. Global burden of disease attributable to mental and substance use disorders: findings from the Global Burden of Disease Study 2010. Lancet. 2013;382(9904): $1575-1586$. 
60. Boutwell AE, Allen SA, Rich JD. Opportunities to address the hepatitis C epidemic in the correctional setting. Clin Infect Dis. 2005; 40 Suppl 5:S367-S372.

61. Younossi ZM, Stepanova M, Afendy M, Lam BP, Mishra A. Knowledge about infection is the only predictor of treatment in patients with chronic hepatitis C. J Viral Hepat. 2013;20(8):550-555.

62. Centers for Disease Control and Prevention (CDC). Vital signs: evaluation of hepatitis $\mathrm{C}$ virus infection testing and reporting - eight US sites, 2005-2011. MMWR Morb Mortal Wkly Rep. 2013;62(18): $357-361$

63. Klevens RM, Miller J, Vonderwahl C, et al. Population-based surveillance for hepatitis C virus, United States, 2006-2007. Emerg Infect Dis. 2009;15(9):1499-1502.

64. Jordan AE, Masson CL, Mateu-Gelabert P, et al. Perceptions of drug users regarding hepatitis $\mathrm{C}$ screening and care: a qualitative study. Harm Reduct J. 2013;10:10.

65. Singer ME, Younossi ZM. Cost effectiveness of screening for hepatitis C virus in asymptomatic, average-risk adults. Am J Med. 2001;111(8): 614-621.

66. Kim AY, Nagami EH, Birch CE, Bowen MJ, Lauer GM, McGovern BH. A simple strategy to identify acute HCV infection among newly incarcerated injection drug users. Hepatology. 2013; 57(3):944-952.

67. Taylor LE, DeLong AK, Maynard MA, et al. Acute hepatitis C virus in an HIV clinic: a screening strategy, risk factors, and perception of risk. AIDS Patient Care STDs. 2011;25(10):571-577.
68. Linas BP, Wong AY, Schackman BR, Kim AY, Freedberg KA. Costeffective screening for acute hepatitis $\mathrm{C}$ virus infection in $\mathrm{HIV}$-infected men who have sex with men. Clin Infect Dis. 2012;55(2):279-290.

69. Arora S, Thornton K, Murata G, et al. Outcomes of treatment for hepatitis C virus infection by primary care providers. $N$ Engl J Med. 2011;364(23):2199-2207.

70. Centers for Disease Control and Prevention. CDC-RFA-PS14-1413; Community-based Programs to Test and Cure Hepatitis C. Washington, DC: Grants.gov; 2014. Available from: http://www.grants.gov/web/ grants/view-opportunity.html?oppId=252867. Accessed March 18, 2014.

71. Staton T. Activists pounce on $\$ 1,000-$ - - day price for Gilead's hep C wonder drug, Sovaldi. FiercePharma. December 9, 2013. Available from: http://www.fiercepharma.com/story/activists-pounce-1000day-price-gileads-hep-c-wonder-drug-sovaldi/2013-12-09. Accessed February 19, 2014.

72. Galbraith JW, Franco RA, Rodgers JB, et al. LB-6; screening in emergency department identifies a large cohort of unrecognized chronic hepatitis $\mathrm{C}$ virus infection among baby boomers. The Liver Meeting; November 1-5, 2013; Washington, DC.

73. Perez-Latorre L, Sanchez-Conde M, Rincon D, et al. Prediction of liver complications in patients with hepatitis $\mathrm{C}$ virus-related cirrhosis with and without HIV coinfection: comparison of hepatic venous pressure gradient and transient elastography. Clin Infect Dis. 2014;58(5):713-718.
Hepatic Medicine: Evidence and Research

\section{Publish your work in this journal}

Hepatic Medicine: Evidence and Research is an international, peerreviewed, open access journal covering all aspects of adult and pediatric hepatology in the clinic and laboratory including the following topics: Pathology, pathophysiology of hepatic disease; Investigation and treatment of hepatic disease; Pharmacology of drugs used for

\section{Dovepress}

the treatment of hepatic disease. Issues of patient safety and quality of care will also be considered. The manuscript management system is completely online and includes a very quick and fair peer-review system, which is all easy to use. Visit http://www.dovepress.com/ testimonials.php to read real quotes from published authors.

Submit your manuscript here: http://www.dovepress.com/hepatic-medicine-evidence-and-research-journal 